\title{
Modernisation of the underground coal mining sector in Colombia - a proposal from the academy
}

\author{
JM Salamanca Universidad Pedagógica y Tecnológica de Colombia, Colombia \\ OO Rodriguez-Diaz Universidad del Valle, Colombia
}

AA Fernández Servicio Nacional de Aprendizaje, Colombia

JJ Niño-Merchan Universidad Pedagógica y Tecnológica de Colombia, Colombia

B Rojas Universidad Pedagógica y Tecnológica de Colombia, Colombia

\begin{abstract}
Mining has provided major developments and resources to countries that produce raw materials, but in developing countries, such as Colombia, there is little technology and research in the area of mining processes. This has serious consequences on aspects such as worker safety, environmental impact and mining production. Thus, in Colombia, for underground coal mining, statistics on deaths, accidents and damage to the environment are high.

This paper presents the proposal of a research project between the Universidad Pedagógica y Tecnológica de Colombia (UPTC) and the Centro Nacional de Minería del Servicio Nacional de Aprendizaje (SENA) that seeks to reduce the technological and research gap of the sector in underground coal mining in Colombia. The proposed project highlights the importance of developing scientific research processes and the application of industrial automation processes in small and medium-sized coal mines, taking into account the needs of safety, environmental impact and operating conditions. The proposal is based on two stages. The first stage is the appropriation of technology in the coal mining sector in Colombia, and the second stage presents the methodology for the development of the objectives, seeking to solve the identified problem.

As a consequence of the analysis, the following three fundamental problems were detected: a low level of safety and productivity research for underground coal mining in Colombia, low transfer of technology in the mining sector, and low appropriation of knowledge on issues related to the application of new technologies in underground coal mining. The proposed methodology is based on addressing the three identified problems, generating objectives for each of them as follows: undertake research on safety, productivity and environmental impact on underground coal mining in Colombia; increase technological transfer in the mining sector; and increase social appropriation of knowledge on issues related to the application of new technologies in underground coal mining.

For generating research, the research groups associated with UPTC and SENA will develop projects linked to MS, MSc and PhD programs that address associated problems in areas such as ventilation, ground support and environmental impact. For the appropriation of knowledge, socialisation and training activities are offered to companies and workers at all levels of the sector.

The proposed activities will be developed in the UPTC and SENA laboratories, and will be validated in the only didactic mine in Latin America for underground coal mining works; a mine belonging to SENA and located in the department of Boyacá, Colombia.
\end{abstract}

Keywords: security in mining, ventilation, coal, automatic control 


\section{Introduction}

Colombia is located in the northern part of South America; an area that hosts a remarkable amount of mining activity, particularly coal mining. According to the World Energy Statistical Review of 2013 published by BP p.I.c (2014), Colombia occupies the eleventh place in coal production worldwide, behind China, the United States, India and the European Union, amongst others, and is the largest producer of coal in Latin America. Colombia is the fourth largest exporter of coal, after the United States, China and Australia, with reserves estimated at about 17 billion tons, of which seven billion tons have been sold. In 2011, national production increased by $15.4 \%$ to 85.8 million tons, and exports totalled 8.397 billion tons. This positive result has several explanations. One of them is that the product is of excellent quality, much of which is the best quality of exported coal in terms of calorific value and low concentration of ash.

It is important to note that the geological, geographic and socioeconomic conditions of coal mining in Colombia are quite different compared to other countries. Coal mining in Colombia is carried out in two ways; open pit and underground mining. The departments in which coal is most exploited underground are Santander, Cundinamarca and Boyacá. Some $72 \%$ of such mines are considered small mining, $26 \%$ are considered medium mining and only $2 \%$ are considered large mining. According to the national mining census 2012 , $47 \%$ of mining production units exploit non-metallic minerals, followed by $31 \%$ of mining production units that exploit metallic minerals, while $22 \%$ are engaged in mining coal and only $2 \%$ mine precious stones (Güiza 2013). In Colombia in 2011, there were 14,357 mining production units, of which only $37 \%$ had mining titles while the remaining $63 \%$ did not (Ministry of Mines and Energy Colombia \& National Mining Agency 2012). In the same way, the aforementioned study shows that more than $72 \%$ of Colombian mining production units have less than six workers, that $60 \%$ of the miners in the country have a level of education that only reaches basic primary education, and that some $10 \%$ are illiterate.

Underground coal mining in Colombia has serious security problems. According to the Ministry of Mines and Energy Colombia and National Mining Agency (2016), 15 deaths have occurred so far this year in the department of Boyacá. The safety problem associated with underground coal mining in Colombia is rooted in the scarce implementation of modern techniques and technologies for the extraction of coal and in the culture of the population. More than $67 \%$ of the existing mining production units in the country do not use any type of business tool (accounting, inventory, among others) for the management of their business. This deficiency is present for almost all informal companies (Ministry of Mines and Energy Colombia \& National Mining Agency 2016). This makes evident the chances of survival of this type of company in a nationally or internationally competitive field. Likewise, only $28 \%$ of companies implement some type of action with regard to safety, hygiene and occupational health which shows the risk that the workers of the great majority of companies in the sector face.

This scenario is repeated in relation to environmental permits and licences; more than $75 \%$ of mining units in Colombia do not have environmental permits or licenses. Small and medium-sized mining operations in Colombia are characterised by the absence or very small degree of mechanisation, the exploitation of small or marginal deposits (not economically exploitable through mechanised mining), a high labour component (semi-skilled and unskilled), and low levels of productivity and efficiency in mineral exploitation and processing. Low levels of wages and income, high levels of illegality (lack of mining title), lack of social security for workers, a low level of industrial safety and high environmental impact generate a variable activity developed by small and medium-sized mining companies depending on the mineral price.

According to the Ministry of Mines and Energy Colombia and National Mining Agency (2016), the statistics of mining emergencies reported from 2010 to the first half of 2014 show a trend towards a decrease in the level of casualties with fatalities. However, in 2015 and 2016 emergencies increased, generating a high interest from the government entities to seek to reduce these incidents. Taking this into account, the Universidad Pedagógica y Tecnológica de Colombia (UPTC) and the Centro Nacional de Minería del Servicio Nacional de Aprendizaje (SENA) constituted a task force, including teachers and researchers from the schools of mining engineering, electronic engineering, industrial engineering and geological engineering and experts of SENA, in 
order to clearly identify the causes of mining accidents, and propose solutions by training and research. In what follows, the results and proposal will be presented to help solve the problem.

This paper is organised as follows: first, the causes of the problem are analysed; second, the problem tree that characterises the problem is shown; third, the importance of mining automation is explained; and fourth, the methodology and the objectives tree are presented. Finally, the activities proposed to develop the proposal and conclusions are given.

\section{Causes of the problem}

Underground coal mining is one of the few industries where technology transfer has been integrated very slowly and has had a low impact. The main problem lies in the low levels of research for the appropriate technological application in underground coal mining in Colombia, as well as scarce scientific research at different levels of the different problems of underground coal mining of Boyacá. This generates a low implementation of techniques and technologies in underground coal mining, producing high levels of accident rates and low competitiveness in the country's coal mining industry. In Colombia, one of the predominant coal mining areas is Boyacá. Coal represents an important item in Boyacá's economy and a key component of its productive identity. In Boyacá, it is estimated that coal mining generates more than 10,000 direct jobs within the 1,700 mines located in most of the provinces of the department; Centro, Valderrama, Norte, Tundama and Sugamuxi, among others.

\subsection{Direct causes}

From a serious and conscientious analysis of the current situation of mining in the region, and taking into account the information provided by the Ministry of Mines and Energy Colombia and National Mining Agency (2016), we identified the following direct causes of employment generation:

- Low allocation of investment resources for research in coal mining.

- Low investment in the technological development of the mining sector.

- Culture of the mining entrepreneur.

- Artisanal underground coal mining.

- Lack of the target population's knowledge of the existence and applicability of modern systems and strategies to improve safety and increase productivity and competitiveness in mining.

\subsection{Indirect causes}

As a result of the studies carried out by the Ministry of Mines and Energy Colombia and National Mining Agency (2016), we identified the following indirect causes of employment generation:

- Poor implementation of techniques and technology.

- Low transfer of technology in the coal mining sector.

- Low levels of research on safety and productivity with regard to coal mining.

- Low social appropriation of knowledge on issues related to security system development for underground coal mining.

Low levels of technological development lead to greater risks. This is evidenced by the high levels of accidents in coal mining. Figure 1 shows the levels of accident rates in mining from 2005 to 2016. Figure 2 shows the causes of several of the accidents that are generated in mining. Some of these could be prevented by applying technology, and training mine workers. 


\section{Reported emergencies}

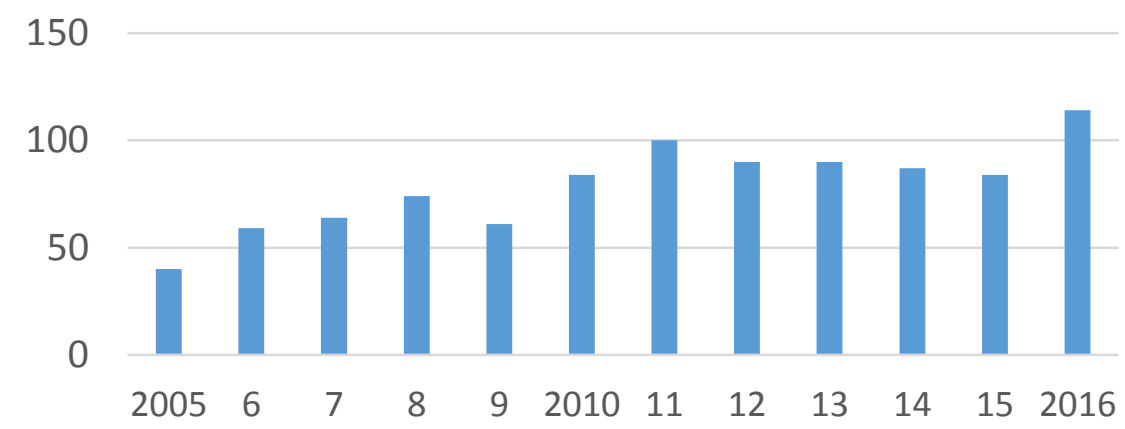

Figure 1 Accident rates in the last 11 years (National Mining Agency 2017)

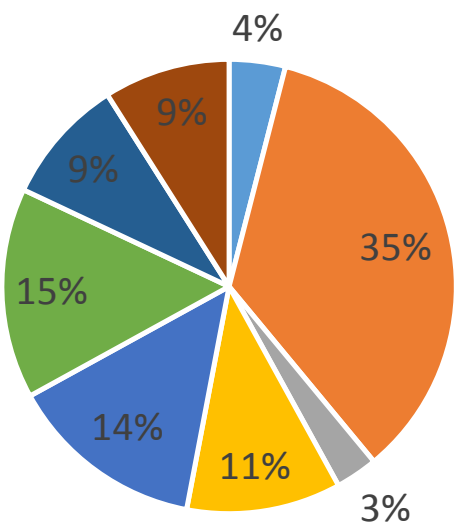

$$
\begin{aligned}
& \text { - Downfall level } \\
& \text { - Collapse } \\
& \text { - Electric } \\
& \text { - mechanic } \\
& \text { - explosion } \\
& \text { - foul air } \\
& \text { - fire } \\
& \text { - Other causes }
\end{aligned}
$$

Figure 2 Causes of mining emergencies in Colombia (National Mining Agency 2017)

The statistics of Figure 1 present an overview of the Colombian mining industry. Figure 2 shows that the main cause of emergencies in mining is the fall of rocks, or landslides. According to the report on mining accidents generated by the National Mining Agency, these incidents are caused by inadequate mining ground support and reinforcement techniques that ensure the support of the roof and sustain a safe working environment for the miners. The most commonly used technique in underground coal mining is wood shoring, but this is used empirically. In some mines, work is done with little or no support installation which generates rockfalls that are difficult to prevent when miners do not have continuous control of the roof of the mine.

The second cause is the unsafe acts and electromechanical accidents generated mainly by a lack of knowledge of safety, and the mine workers' culture of working in an unsafe manner. The low utilisation of equipment technically designed to operate in underground coal mining is also a direct cause that creates risks and could cause greater tragedies if electrical equipment that does not meet safety standards for mining environments with the presence of methane gas.

The third cause of accidents is linked to mine ventilation - inhalation of asphyxiating gases or poisons and the presence of methane gas. This is due to the lack of a ventilation system that ensures adequate airflow to dilute the gases and supply oxygen to the miners operating inside the mine. Ventilation problems are the most serious issue in underground coal mining as they are linked to the second factor of accidents and generate major tragedies and higher levels of fatalities. In the fourth cause of accident levels, we have accidents linked to explosives, floods, fires, etc. Fires and floods, however, present only a very low level of risk in underground coal mines. The use of explosives in coal mining is limited to specific works and little is 
done in medium and small mining operations, which is where they present the biggest cause of accidents. The departments of Boyacá and Cundinamarca encounter the highest accident rates in Colombia (Figure 3). These departments are also the main coal producers in the Andean region (Consorcio Carbonifero \& Unidad de Planeación Minero Energética 2015). Boyacá, for example, is a department that is characterised by strong mining activity, particularly coal. In this region, most coal mining operations are still carried out using artisanal and low technology methods.

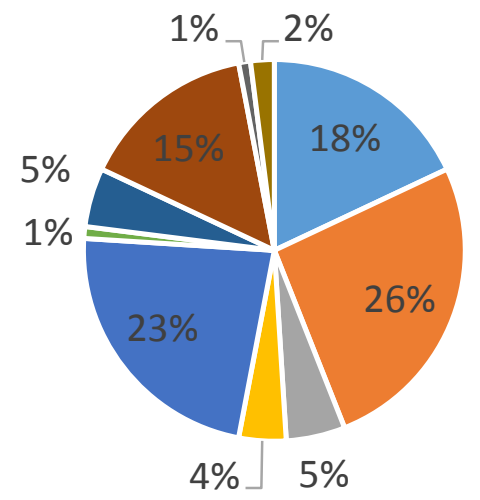

$$
\begin{aligned}
& \text { - Antioquia } \\
& \text { - Boyacá } \\
& \text { - Caldas } \\
& \text { - Cauca } \\
& \text { - Cundinamarca } \\
& \text { - Cesar } \\
& \text { - V.Cauca }
\end{aligned}
$$

Figure 3 Accident levels by department in Colombia (National Mining Agency 2017)

\section{Importance of automation of mines}

The Colombian state issued resolution 1886 in 2015 (Ministry of Mines and Energy 2015), seeking to bring the mining sector closer to the use of new instrumentation technologies. Mine automation is an interesting example of a large-scale complex system with high environmental impact where control strategies can achieve further improvements. At the same time, one of the first objectives of the modern mining industry is to comply with environmental specifications during the extraction and stacking of minerals due to energy consumption or generation of pollution agents (Di Benedetto et al. 2008; Witrant \& Johansson 2008; Liu et al. 2009).

When seeking to reduce production costs and improve the safety of miners, one of the main aspects of underground mining automation is to evaluate the instrumentation used.

The ventilation control system is an essential factor for the operation of a mine in terms of safety (regulation of the gases). Another interesting point is the fact that the savings associated with global control strategies for fluid systems (pumps, fans and compressors) account for approximately $20 \%$ of the total energy savings of the engine operating system. This motivates the development of new control strategies for large-scale aerodynamic processes based on appropriate automation and a global consideration of the system, so it is of great environmental and industrial interest to research automatic control solutions to optimise the amount of pumped air to save on energy consumption (provided that the airflows established by the standards are met).

It is clear that investigating automatic control solutions and minimising the amount of pumped air to save energy consumption (proportional to the cube of airflow quantity) is of great environmental and industrial interest. The management of the air inside the mine includes controlling important variables such as dry and humid air temperature and speed, relative humidity, the level of the gases generated in the operation, and the flow of air circulating in the mine. These variables must be controlled to ensure an adequate level and quality of air circulating within the mine. In a common mine that does not have an automation system, in order to control and know how the air circulates inside the mine, periodic ventilation should be carried out to determine the previous variables (Xu et al. 2015). Through them you can learn about the flow of air that is circulating in a certain point of the mine, the temperature of the location (wet, dry and effective), relative humidity and level of gases present. 
In mines that have software, you can model the ventilation circuit of the mine and perform simulations under different conditions that may arise. However, these aids have a disadvantage if they are not linked to an automation system with real-time control that operates according to environmental conditions within the mine. In this part, it is also vital to mention frequency inverters (VDF). The variation (increase or decrease) of the fan-driven flow rate is possible through the use of VDFs connected to fan motors. Such electrical devices allow the fan motor to be varied locally or remotely and dynamically; that is to say without stopping the fan, the speed of rotation (rpm) of the fan motor, and thus the airflow moved by said equipment, can be altered. In order to achieve such an effect automatically, it is important to have a good control system (Di Benedetto et al. 2008; Hu et al. 2003; Hongqing et al. 2011). An important point of a ventilation automation system is to have adequate sensors that support the mining environment and ensure a reliable transmission of the information of the physical variables. These technologies can send information by wire or wirelessly (Witrant et al. 2010, 2008). The technological challenge of automating a ventilation system is to ensure that readings given by the sensors located inside the mine send signals to the command centre, so that it is possible to act on the fans according to the existing needs of airflow.

\section{$4 \quad$ Methodology}

From the detailed study, much analysis and discussion (approximately two months), and consideration of the types of problems posed by coal mining in Colombia with its socio-economic characteristics, the task force proposed a methodology based on theoretical research, practical experimentation and site investigation of the mines of the region. The first activity developed by the team, once the causes of the problem were identified, was to establish the tree of problems in which the causes and effects of the situation are summarised (Figure 4).

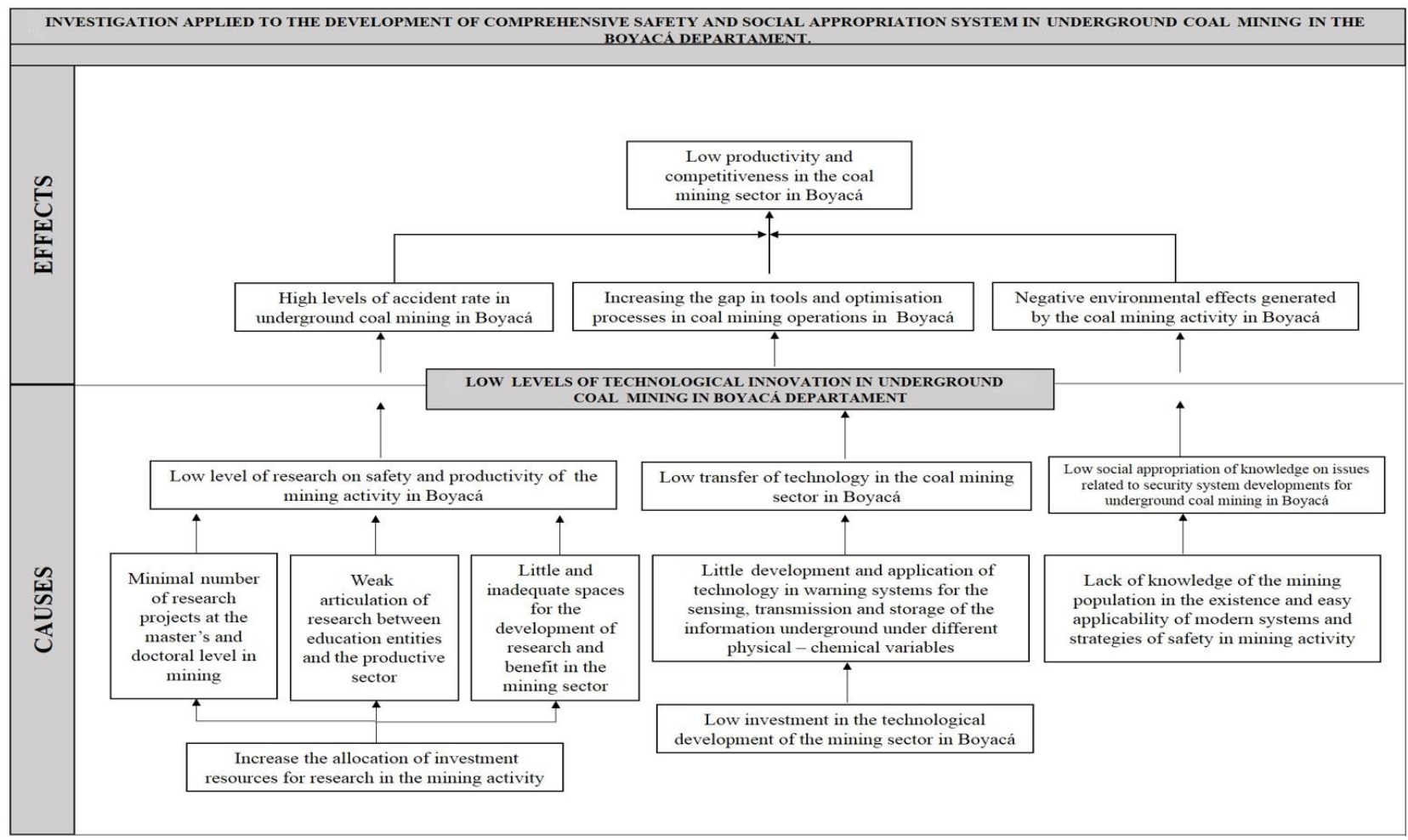

Figure 4 Problem tree systematically identifying the problem in order to adequately formulate project objectives

The task force then proposed the following objectives and outlined them in the objectives tree shown in Figure 5. 


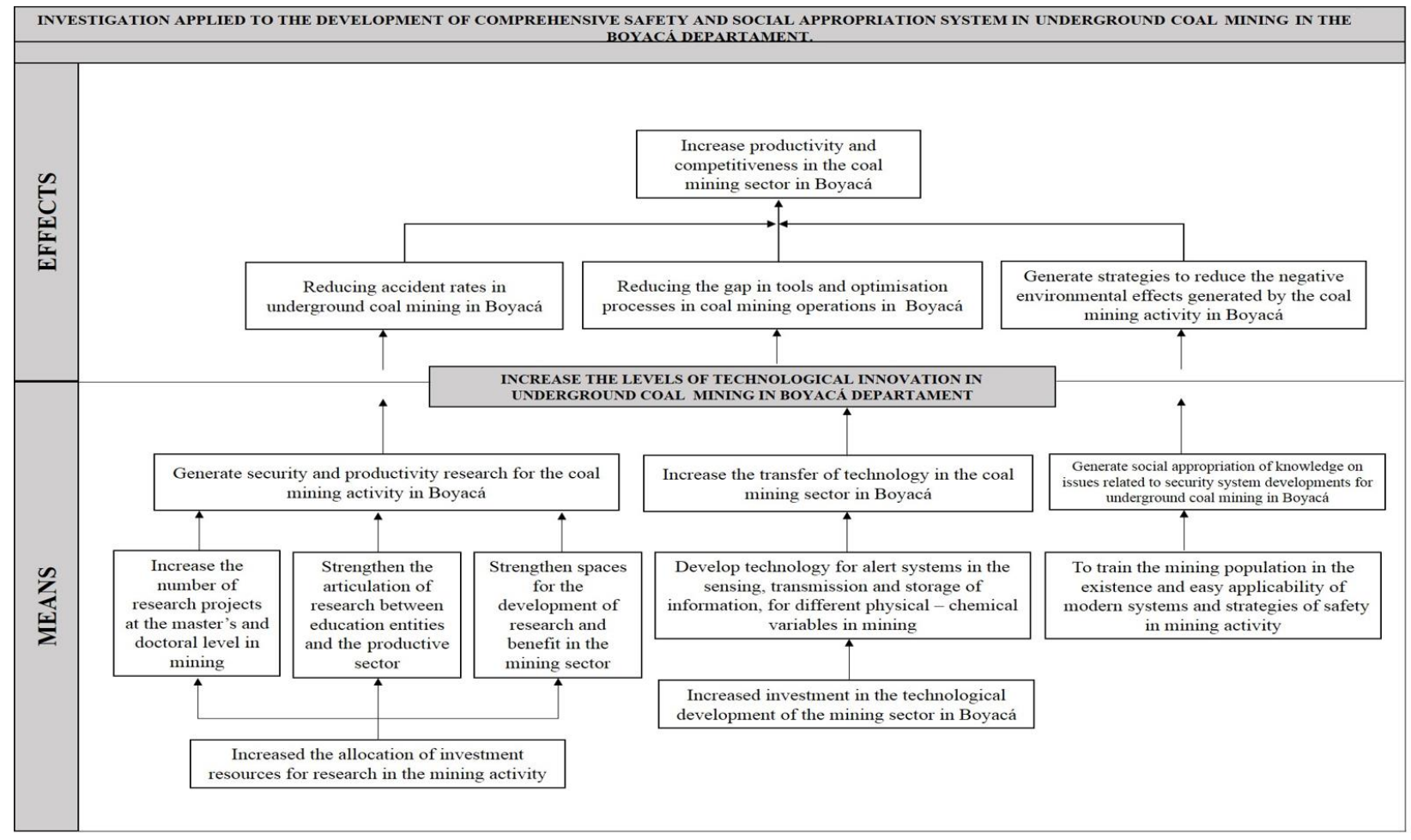

Figure 5 Lens tree illustrating how to address the problems identified and raised in the problem tree

\subsection{General objective}

Taking into account the technological deficiencies and the socio-cultural conditions that are present in the coal mining sector, the task force poses as a general objective the following:

- To increase the levels of research in underground coal mining in Colombia.

\subsection{Specific objectives}

In accordance with the general objective, the following specific objectives are proposed:

- Generate research on safety and productivity with regard to coal mining in Colombia.

- Increase the transfer of technology in the coal mining sector in Colombia.

- Generate social appropriation of knowledge on issues related to security system development for underground coal mining in Colombia.

Taking into account the analysis of the previous problem, the team proposed the tree of objectives shown in Figure 5.

In order to fulfil each objective in a coordinated way, activities were proposed to be classified into components depending on the scientific specificities, knowledge, techniques and technologies used in the modern processes of exploitation in a coal mine.

\subsection{Activities}

Based on the objectives outlined in Section 4.2, the task force generated three components:

- Component C1: generate security and technology research.

- Component C2: increase research to improve technology transfer. 
- Component C3: generate social appropriation of knowledge in aspects related to the development of security and technology systems.

To achieve what was stated in the previous components, the following activities must be carried out: technology development, technology transfer, training, and support in implementation.

Figure 6 shows the components of the project and the generation of activities to meet the objectives proposed.

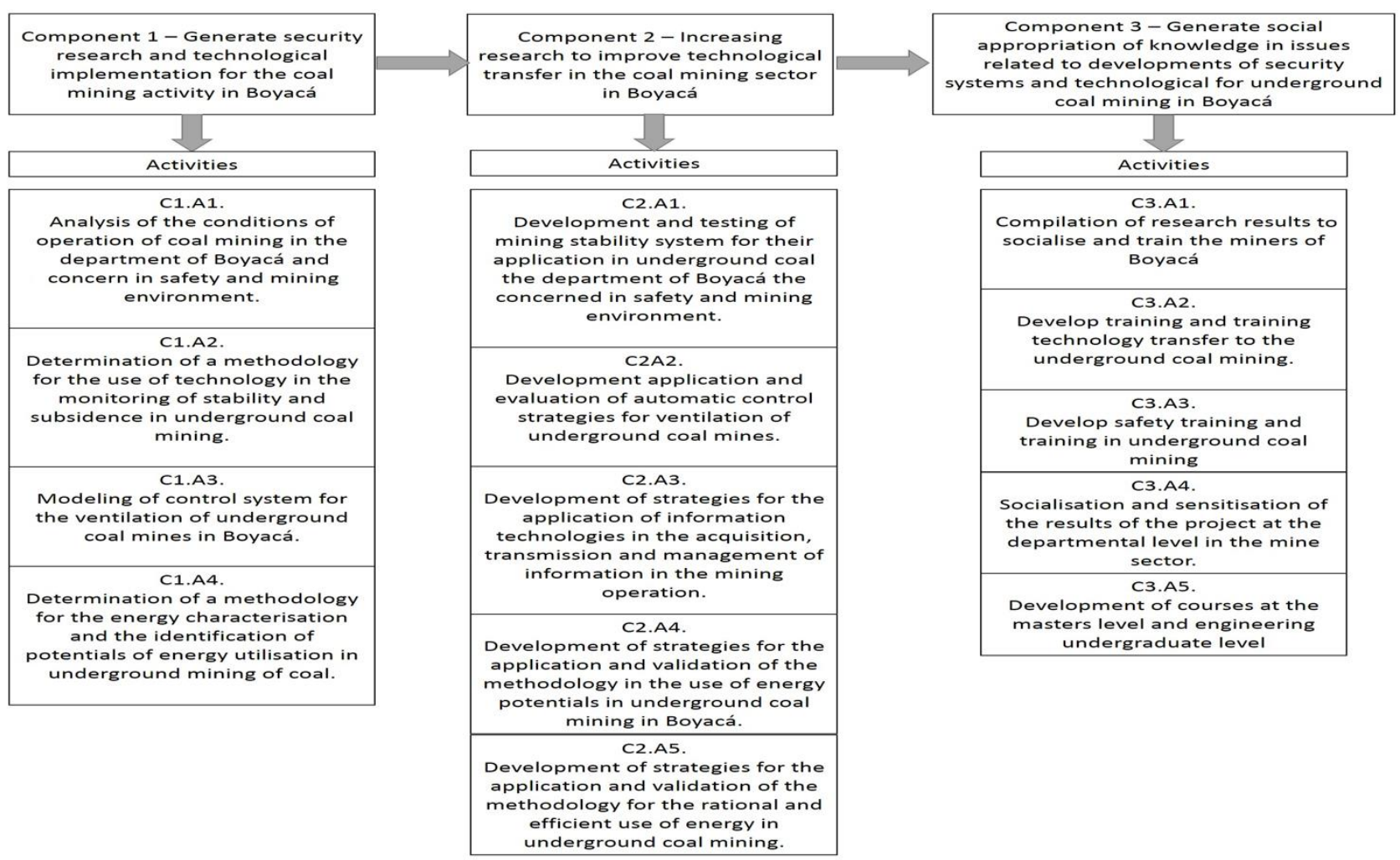

Figure 6 Activities presented, seeking to cover the identified and planned topics in the objectives tree

The proposed activities will be carried out in the National Mining Centre's teaching mine. This mine is a prototype to test ventilation control strategies and new machinery and technologies. The National Mining Centre's teaching mine has an internal network of communications, sensorial gases in the extraction fronts, and machinery used in underground coal mining.

\section{Conclusion}

A research proposal is presented, based on the methodology required by the central government, and a proposal developed by the research groups belonging to higher education institutions in Colombia, in order to strengthen the appropriation of technology and new knowledge in the area of mining production, specifically for underground coal mining. The proposal seeks to strengthen and use the current tools available in the Didactic mine of the National Learning Service, as it is the only educational mine in Latin America to teach new technologies in the sector, as well as to reduce the gap between training institutions and the companies producing coal.

\section{Acknowledgement}

The authors thank all those who contributed to the construction of this proposal, especially Diego Sanabria, Liliana Fernández, Camilo Sanabria, Ariel Mesa, Wilson Pérez, Consuelo Ruiz and Claudia Gutiérrez. 


\section{References}

BP p.l.c 2014, BP Statistical Review of World Energy June 2014, BP Global, viewed 10 August 2017, http://www.bp.com/content/dam/bpcountry/de_de/PDFs/brochures/BP-statistical-review-of-world-energy-2014-full-report.pdf

Consorcio Carbonifero \& Unidad de Planeación Minero Energética 2015, Análisis de la estructura de costos de la minería y transporte asociado por escalas de producción de carbón en los departamentos de Norte de Santander, Santander, Boyacá y Cundinamarca, Unidad de Planeación Minero Energética, Bogota, viewed 10 August 2017, http://www.upme.gov.co/SeccionMineria_sp/ANALISIS_ESTRUCTURA_DE_COSTOS_DE_MINERIA_TRANSPORTE.pdf

Di Benedetto, MD, D'Innocenzo, A, Serra, E \& Witrant, E 2008, 'Automatic verification of wireless control in a mining ventilation system', Proceedings of the 2008 IEEE International Conference on Automation Science and Engineering, Institute of Electrical and Electronics Engineers, Piscataway, pp. 845-850.

Güiza, L 2013, 'La pequeña minería en Colombia: una actividad no tan pequeña', Revista DYNA, vol. 80, no. 181, pp. 109-117, viewed 10 August 2017, http://revistas.unal.edu.co/index.php/dyna/article/view/35819

Hongqing, Z, Zeyang, S, Meiqun, Y, Zheng, L \& Jian, L 2011, 'Theory study on nonlinear control of ventilation network airflow of mine', Procedia Engineering, vol. 26, pp. 615-622.

Hu, Y, Koroleva, OI \& Krstić, M 2003, 'Nonlinear control of mine ventilation networks', Systems \& Control Letters, vol. 49, no. 4, pp. 239-254.

Liu, G, Gao, F, Ji, M \& Liu, X 2009, 'Investigation of the ventilation simulation model in mine based on multiphase flow', Procedia Earth and Planetary Science, vol. 1, no. 1, pp. 491-496.

National Mining Agency 2017, Estadísticas Emergencias Diciembre 2016, 2016 Mining Safety and Rescue Group, National Mining Agency, Bogota.

Ministry of Mines and Energy Colombia \& National Mining Agency 2016, Estadisticas Emergencias Agosto 2016, 2016 Mining Safety and Rescue Group, National Mining Agency, Bogota.

Ministry of Mines and Energy 2015, Reglamento de Seguridad en las Labores Mineras Subterráneas, Decreto 1886, 21 September 2015, Ministry of Mines and Energy, Bogota, viewed 10 August 2017, https://www.minminas.gov.co/documents/ 10180/698204/DOCUMENTO_ReglamentoSeguridadMineriaSubterranea.pdf/774e58ab-d35d-4d92-8e7e-fd63ec127216

Ministry of Mines and Energy Colombia \& National Mining Agency 2012, Censo Minero Departamental 2010-2011, Ministry of Mines and Energy, Bogota.

Witrant, E, D'Innocenzo, A, Isaksson, AJ, Di Benedetto, MD, Johansson, KH, Santucci, F \& Strand, M 2008, 'Mining ventilation control: a new industrial case for wireless automation', Proceedings of the 2008 IEEE International Conference on Automation Science and Engineering, Institute of Electrical and Electronics Engineers, Piscataway.

Witrant, E, D'Innocenzo, A, Sandou, G, Santucci, F, Di Benedetto, MD, Isaksson, AJ ... Tiberi, U 2010, 'Wireless ventilation control for large-scale systems: the mining industrial case', International Journal of Robust and Nonlinear Control, vol. 20, no. 2, pp. 226-251.

Witrant, E \& Johansson, KH 2008, 'Air flow modeling in deepwells: application to mining ventilation', Proceedings of the 2008 IEEE International Conference on Automation Science and Engineering, Institute of Electrical and Electronics Engineers, Piscataway, pp. 845-850.

Xu, G, Jong, EC, Luxbacher, KD, Ragab, SA \& Karmis, ME 2015, 'Remote characterization of ventilation systems using tracer gas and CFD in an underground mine', Safety Science, vol. 74, pp. 140-149. 
